\title{
PYRIDOSTIGMINE-INDUCED MICROCEPHALY
}

The association of high-dose pyridostigmine (PYD) during pregnancy with microcephaly and CNS injury in an infant is reported from the Children's Hospital Los Angeles, CA. The mother was diagnosed with myasthenia gravis (MG) at 10 years of age, and had undergone thymectomy and plasmapheresis. PYD was the only medication during pregnancy, and the dose was increased steadily because of persistent diplopia and ptosis. The dose of $40 \mathrm{mg} / \mathrm{kg}$ day (average of 1500-3000 g/day) continued for the entire pregnancy was four to eight times the usual recommended amount. The infant delivered by cesarean section at 36 weeks because of fetal bradycardia weighed $1880 \mathrm{~g}(<2 \%)$ and the head circumference (HC) was $33.5 \mathrm{~cm}(10 \%)$. Apgars were 3 and 8 . He was hypotonic with poor respiratory efforts and required intubation. A Tensilon test was positive for neonatal $\mathrm{MG}$, and he was treated by exchange transfusion and IV immunoglobulin. He was weaned from the respirator at 3.5 months. At 3 months his $\mathrm{HC}$ was $37 \mathrm{~cm}(<5 \%)$, and at 5 months, it was $38 \mathrm{~cm}(<2 \%)$. He had dysmorphic facial features, short neck, broad chest, campylodactyly, bilateral cryptorchidism, and ankle clonus. MRI revealed mild ventriculomegaly. (Niesen CE, Shah NS. Pyridostigmine-induced microcephaly. Neurology May (1 of 2) 2000;54:1873-1874). (Reprints: Dr CE Niesen, Department of Pediatrics, Cedars-Sinai Medical Center, 8700 Beverly Blvd, Room 1165W, Los Angeles, CA 90048).

COMMENT. Pyridostigmine, a cholinesterase inhibitor, has been used safely in pregnant myasthenic patients in doses less than $600 \mathrm{mg} / \mathrm{day}$. This is the first report of high-dose PYD being associated with microcephaly, growth retardation, and evidence of CNS damage in the infant. PYD passes readily into the fetal circulation, with concentrations amounting to $90 \%$ of the maternal plasma levels.

\section{TOXIC DISORDERS}

\section{METHYLMERCURY-INDUCED FETAL NEUROLOGIC DYSFUNCTION}

The effects of seafood contaminants in maternal diet during pregnancy on neonatal neurologic function were examined in 182 singleton term births in the Faeroe Islands, and reported from the Institute of Public Health, Odense University, Denmark. Maternal serum, hair, and milk and umbilical cord blood were analysed for contaminants, Each infant's neurologic optimality score (NOS) was determined at 2 weeks of age and adjusted for gestational age. Exposures to methylmercury and polychlorinated phenols and cord blood fatty acid concentrations were increased in proportion to maternal seafood intake. Thyroid function tests were normal. A 10-fold increase of cord-blood mercury concentration was correlated with a decrease in NOS of $2.0(\mathrm{P}=.03)$. (Steuerwald $\mathrm{U}$, Weihe P, Jorgensen PJ et al. Maternal seafood diet, methylmercury exposure, and neonatal neurologic function. L Pediatr May 2000;136:599-605). (Reprints: Philippe Grandjean MD PhD, Institute of Public Health, Odense University, Winslowparken 17, 5000 Odense C, Denmark).

COMMENT. Increased exposures to methylmercury from maternal seafood intake are associated with a significant decrease in neonatal neurologic optimality scores and an increased risk of neurodevelopmental deficit. The NOS used in this study is based on the Prechtl exam technique and includes functional abilities, reflexes and tone, and behavior. The NOS is the number of items rated optimal out of 60 . In the Faeroe Islands, whale meat is the source of 